\title{
Direct and Systemic Administration of a CNS-Permeant Tamoxifen Analog Reduces Amphetamine-Induced Dopamine Release and Reinforcing Effects
}

\author{
Colleen Carpenter ${ }^{1,5}$, Alexander G Zestos ${ }^{1,2,5}$, Rachel Altshuler', Roderick J Sorenson ${ }^{3,4}$, Bipasha Guptaroy', \\ Hollis D Showalter ${ }^{3,4}$, Robert T Kennedy ${ }^{1,2}$, Emily Jutkiewicz' and Margaret E Gnegy*,I \\ 'Department of Pharmacology, University of Michigan, Ann Arbor, MI, USA; '2Department of Chemistry, University of Michigan, Ann Arbor, MI, USA; \\ ${ }^{3}$ Department of Medicinal Chemistry, University of Michigan, Ann Arbor, MI, USA; ${ }^{*}$ Vahlteich Medicinal Chemistry Core, University of Michigan, Ann \\ Arbor, MI, USA
}

Amphetamines (AMPHs) are globally abused. With no effective treatment for AMPH addiction to date, there is urgent need for the identification of druggable targets that mediate the reinforcing action of this stimulant class. AMPH-stimulated dopamine efflux is modulated by protein kinase C (PKC) activation. Inhibition of PKC reduces AMPH-stimulated dopamine efflux and locomotor activity. The only known CNS-permeant PKC inhibitor is the selective estrogen receptor modulator tamoxifen. In this study, we demonstrate that a tamoxifen analog, 6c which more potently inhibits PKC than tamoxifen but lacks affinity for the estrogen receptor, reduces AMPHstimulated increases in extracellular dopamine and reinforcement-related behavior. In rat striatal synaptosomes, $\mathbf{6 c}$ was almost fivefold more potent at inhibiting AMPH-stimulated dopamine efflux than $\left[{ }^{3} \mathrm{H}\right]$ dopamine uptake through the dopamine transporter (DAT). The compound did not compete with $\left[{ }^{3} \mathrm{H}\right] \mathrm{WIN} 35,428$ binding or affect surface DAT levels. Using microdialysis, direct accumbal administration of I $\mu M$ 6c reduced dopamine overflow in freely moving rats. Using LC-MS, we demonstrate that $\mathbf{6 c}$ is CNS-permeant. Systemic treatment of rats with $6 \mathrm{mg} / \mathrm{kg} \mathbf{6 c}$ either simultaneously or $18 \mathrm{~h}$ prior to systemic AMPH administration reduced both AMPHstimulated dopamine overflow and AMPH-induced locomotor effects. Finally, $18 \mathrm{~h}$ pretreatment of rats with $6 \mathrm{mg} / \mathrm{kg} \mathbf{6 c}$ s.c. reduces AMPH-self administration but not food self-administration. These results demonstrate the utility of tamoxifen analogs in reducing AMPH effects on dopamine and reinforcement-related behaviors and suggest a new avenue of development for therapeutics to reduce AMPH abuse.

Neuropsychopharmacology (2017) 42, 1940-1949; doi:I0.1038/npp.2017.95; published online I4 June 2017

\section{INTRODUCTION}

Amphetamine (AMPH) and its congeners are highly addictive stimulants and their abuse remains a significant health, social, and economic burden (Berman et al, 2008; Carvalho et al, 2012). Yet an effective treatment for AMPH abuse remains elusive. Similar to other drugs of abuse, the reinforcing effects of AMPH are attributed to its ability to significantly increase extracellular dopamine in the nucleus accumbens (Di Chiara and Imperato, 1988; Wise and Bozarth, 1985). AMPH achieves this effect through its action at the dopamine transporter (DAT). The primary role of DAT is to clear extracellular dopamine, thereby terminating presynaptic and postsynaptic dopamine signaling (Zhu and

*Correspondence: Dr ME Gnegy, Department of Pharmacology, University of Michigan, 2220E MSRB III, II 50 W. Medical Center Drive, Ann Arbor Ml 48I09, USA, Tel: + I 734763 5358, Fax: + I 734 763 4450; E-mail: pgnegy@umich.edu

${ }^{5}$ These authors are co-first authors.

Received 8 March 2017; revised 29 April 2017; accepted 3 May 2017; accepted article preview online II May 2017
Reith, 2008). AMPH, a substrate of DAT, disrupts this process by competitively blocking dopamine reuptake and also promoting reverse transport of dopamine via DAT (McMillen, 1983). Unlike stimulants such as cocaine, whose actions are more reliant on storage pools of monoamines, the release of newly synthesized dopamine also contributes to AMPH action (Chiueh and Moore, 1975; Parker and Cubeddu, 1986).

We found that protein kinase $\mathrm{C}(\mathrm{PKC})$ enhances AMPHstimulated dopamine efflux. AMPH increases striatal particulate PKC activity (Giambalvo, 1992, 2004) and PKC stimulates the phosphorylation of $\mathrm{N}$-terminal DAT residues (Foster et al, 2002). Phosphorylation of DAT is permissive for AMPH-stimulated dopamine release (Khoshbouei et al, 2004; Wang et al, 2016). Selective PKC inhibitors and genetic deletion of PKC significantly reduce AMPH-stimulated dopamine release from striatal synaptosomes and slices (Chen et al, 2009; Kantor and Gnegy, 1998). PKC inhibition, however, does not alter the normal uptake functioning of the transporter (Johnson et al, 2005; Kantor and Gnegy, 1998; 
Zestos et al, 2016). Therefore, PKC represents a novel therapeutic target for the treatment of AMPH abuse.

The selective estrogen receptor (ER) modulator tamoxifen stands as the only commercially available central nervous system (CNS)-permeant PKC inhibitor (Zarate and Manji, 2009). Tamoxifen is commonly used to reduce ER-positive breast cancer recurrence and to prevent breast cancer in high-risk women (Fisher et al, 1998; Jordan, 2003). Early reports using purified PKC show that tamoxifen inhibits the calcium- and phospholipid-dependent activity of classical PKC isoforms, with $\mathrm{IC}_{50}$ s between 25 and $100 \mu \mathrm{M}$ (Su et al, 1985). In cells, tamoxifen inhibits PKC at more pharmacologically relevant concentrations (1-5 $\mu \mathrm{M})$ (Gundimeda et al, 1996; Horgan et al, 1986; Lien et al, 1991; O'Brian et al, 1985). There are findings that suggest PKC activity is elevated in patients suffering from bipolar mania, a disorder modeled by repeated AMPH administration in animals (Wang and Friedman, 1996). Interestingly, systemic tamoxifen reduces manic symptoms in patients with bipolar mania, and this effectiveness is believed to stem from the action of tamoxifen at PKC (Kulkarni et al, 2006; Zarate et al, 2007). These data point to the clinical relevance of tamoxifen as a CNS-permeant PKC inhibitor. Although tamoxifen is well tolerated overall, it can cause ER-mediated adverse effects, including increased risk of hot flashes, thromboembolisms, and endometrial cancers (Fisher et al, 1998; Gradishar, 2004). Therefore, a CNS-permeant tamoxifen analog lacking ER activity could be useful in the context of AMPH abuse treatment.

Extensive structure-activity relationship (SAR) studies have investigated tamoxifen substructures that contribute to its ability to bind to the ER and inhibit PKC (de Medina et al, 2004). We used this wealth of knowledge to synthesize a new generation of tamoxifen analogs with increased selectivity for PKC over ER (Carpenter et al, 2016). In this paper, we investigate the effect of our most promising novel compound, $\mathbf{6 c}$ (Figure 1a), at DAT and also on the neurochemical, behavioral, and reinforcing actions of AMPH. Our key findings show that $\mathbf{6 c}$ modulates DAT asymmetrically, in that it is more potent in reducing dopamine efflux than uptake. Importantly, intra-accumbal and systemic administration of the tamoxifen analog significantly reduces dopamine overflow and locomotion stimulated by AMPH. Finally, our self-administration studies demonstrate that $\mathbf{6 c}$ effectively reduces AMPH selfadministration but not food self-administration. This work supports the repurposing of the tamoxifen scaffold as a treatment for AMPH abuse and elucidates an effective route for blocking AMPH reinforcement.

\section{MATERIALS AND METHODS}

\section{Compounds}

6c $(6 \mathrm{c} \cdot 2.5 \mathrm{HCl})$ was synthesized and provided by the Vahlteich Medicinal Chemistry Core at the University of Michigan (Carpenter et al, 2016). D-amphetamine hemisulfate, dopamine, nomifensine maleate salt, and phorbol-12myristate-13-acetate (PMA) were purchased from SigmaAldrich. Ruboxistaurin and cocaine hydrochloride were provided by NIDA-NIH. $\left[{ }^{3} \mathrm{H}\right]$ Dopamine and $\left[{ }^{3} \mathrm{H}\right]$ WIN $35,428 \quad((-)-2-\beta$-carbomethoxy-3- $\beta$-(4-fluorophenyl) tropane-1,5-napthalenedisulfonate) were purchased from Perkin Elmer. Heparin was purchased from Sagent Pharmaceuticals.

\section{Animals}

Animal use and procedures were approved by the Institutional Animal Care and Use Committee at the University of Michigan and followed the guidelines put forth by the National Institutes of Health. Male Sprague Dawley rats were purchased from Envigo and were maintained on a 12-h light cycle with lights on at 0700 hours and all experiments were performed during the light phase. For in vitro experiments, the rats were 7-12 weeks old. The age of rats for microdialysis and self-administration ranged from 7 weeks to 10 months. During self-administration, the rats were food restricted to $80-85 \%$ of their free-feeding body weight and given free access to water.

\section{Synaptosome Preparation}

Rat striata were dissected on ice and homogenized in 10 volumes of homogenization buffer comprised of $0.32 \mathrm{M}$ sucrose, $1 \mathrm{mM}$ EDTA, and cocktail of protease inhibitors (Complete Mini, Roche), pH 7.4. Homogenates were centrifuged at $3000 \mathrm{rpm}$ for $10 \mathrm{~min}$ and the supernatants were saved. The supernatant fractions were then centrifuged at $14000 \mathrm{rpm}$ for $15 \mathrm{~min}$. For the PKC activity experiments, the supernatants were aspirated and the pellets resuspended in Krebs Ringer buffer (KRB) made of $145 \mathrm{mM} \mathrm{NaCl}, 2.7 \mathrm{mM}$ $\mathrm{KCl}, 1.2 \mathrm{mM} \mathrm{KH}_{2} \mathrm{PO}_{4}, 1.2 \mathrm{mM} \mathrm{CaCl}_{2}$, and $1.0 \mathrm{mM} \mathrm{MgCl}_{2}, \mathrm{pH}$ 7.4. For dopamine uptake and suprafusion experiments, the pellets were resuspended in KRB that included $10 \mathrm{mM}$ glucose, $0.05 \mathrm{mM}$ ascorbic acid, and $0.05 \mathrm{mM}$ pargyline.

\section{PKC Activity Assay}

Synaptosomes were pretreated with $\mathbf{6 c}$ for $1 \mathrm{~h}$ prior to activating PKC with PMA. Synaptosomes were lysed and probed for growth-associated protein-43 (GAP-43) and myristoylated alanine-rich C-kinase substrate (MARCKS) phosphorylation using western blotting. Details regarding the assay and western blotting are in Supplementary Methods.

\section{$\left[{ }^{3} \mathrm{H}\right]$ Dopamine Uptake}

Synaptosomes were treated with $0-3 \mu \mathrm{M} 6 \mathrm{c}$ at $37^{\circ} \mathrm{C}$ for $1 \mathrm{~h}$. $\left[{ }^{3} \mathrm{H}\right]$ Dopamine (PerkinElmer Life Sciences) was added for $3 \mathrm{~min}$ and $\left[{ }^{3} \mathrm{H}\right]$ dopamine uptake was terminated with $5 \mathrm{ml}$ cold KRB. The samples were then rapidly filtered on Fisherbrand GF/C filters and washed with $5 \mathrm{ml}$ of cold KRB twice. Non-specific uptake was determined using $100 \mu \mathrm{M}$ cocaine. Once dried, the filters were counted in a Beckman LS 5801 liquid scintillation counter.

\section{Biotinylation}

The effect of $\mathbf{6 c}$ on DAT surface levels in synaptosomes was investigated with sulfo-NHS-SS-biotin using a method previously described (Furman et al, 2009). See Supplementary Methods for more details. 
a

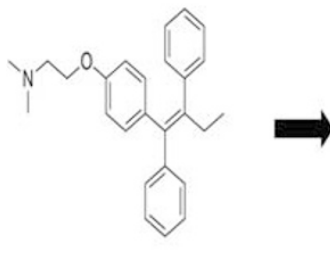

Tamoxifen

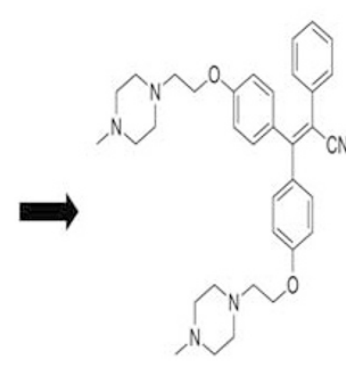

$6 c$

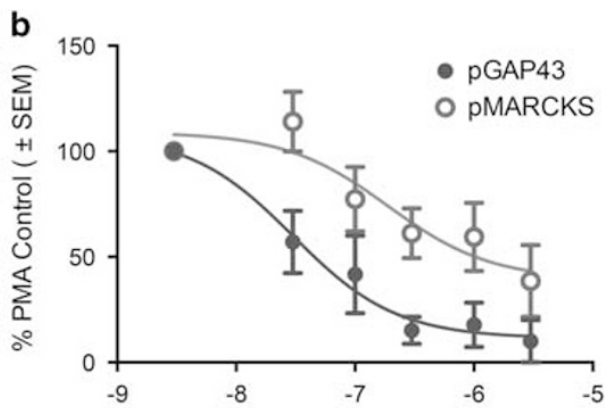

$[6 \mathrm{c}](\mu \mathrm{M})$

C

$[6 c](\mu \mathrm{M})$
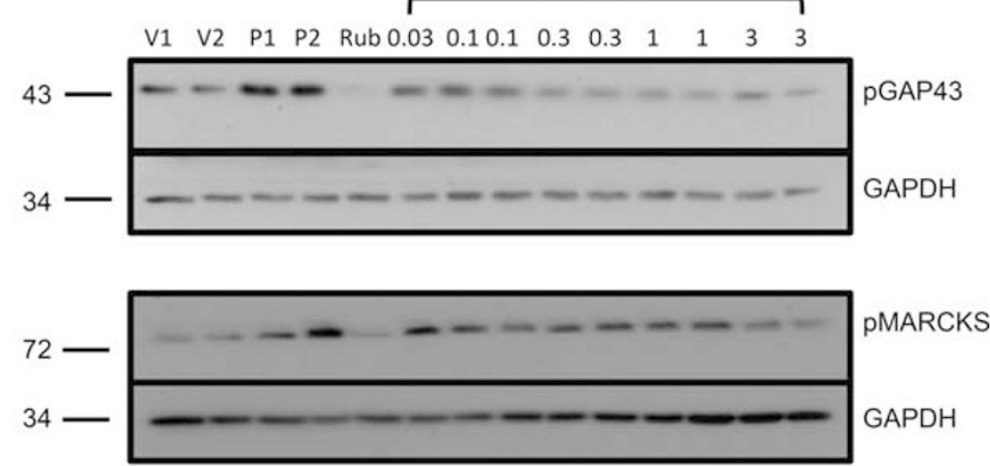

Figure I Structure of tamoxifen analog, 6cc, and its effect on PMA-induced PKC activity in synaptosomes. (a) Structures of tamoxifen and its analog, $\mathbf{6 c}$. (b, c). Rat striatal synaptosomes were incubated in the presence or absence of $\mathbf{6 c}$ for I h at $37^{\circ} \mathrm{C}$. In all, I $00 \mathrm{nM}$ PMA was added for I 5 min to stimulate PKC, and the samples were lysed and probed for phosphoser ${ }^{4}$ _GAP-43 $(n=4)$ and phosphoser ${ }^{152 / 156}$-MARCKS $(n=5)$. GAPDH served as the loading control. (b) Data are represented as the percentage of vehicle optical density and each data set represents mean \pm SEM. (c) Representative western blots. VI, V2: vehicle; PI, P2: PMA control; Rub: 500 nM ruboxistaurin, a control PKC inhibitor.

\section{$\left[{ }^{3}\right.$ H]WIN 35,428 Binding}

Radioligand saturation binding assays were performed by incubating synaptosomes with $3 \mu \mathrm{M} 6 \mathrm{c}$ at $37^{\circ} \mathrm{C}$ for $1 \mathrm{~h}$ followed by $0-200 \mathrm{nM}$ of the cocaine analog $\left[{ }^{3} \mathrm{H}\right]$ WIN 35,428 for $2 \mathrm{~h}$ at $4{ }^{\circ} \mathrm{C}$. Five $\mathrm{ml}$ cold $\mathrm{KRB}$ was then added to samples followed by rapid filtration on Fisherbrand GF/C filters and washed twice with $5 \mathrm{ml}$ of cold KRB. Non-specific binding was determined using $30 \mu \mathrm{M}$ nomifensine.

\section{Suprafusion}

Synaptosomes were loaded onto filters in chambers of a Brandel perfusion apparatus (Brandel SF-12, Gaithersburg, $\mathrm{MD})$ and perfused with $0-3 \mu \mathrm{M} 6 \mathrm{c}$ at $37^{\circ} \mathrm{C}$ for $1 \mathrm{~h}$ at a rate of $400 \mu \mathrm{l} / \mathrm{min}$. Following this wash, 16 fractions were collected in $2 \mathrm{~min}$ increments in vials containing internal standard solution (final concentration $50 \mathrm{mM}$ perchloric acid, $25 \mu \mathrm{M}$ EDTA, and $10 \mathrm{nM} 2$-aminophenol). Dopamine efflux was stimulated by the addition of $10 \mu \mathrm{M}$ AMPH from fractions 6 to 11 . The vehicle control or $\mathbf{6 c}$ was also present during collection. Dopamine was quantified using high-performance liquid chromatography coupled to electrochemical detection (Thermo Scientific/ESA, Sunnyvale, CA).

\section{Microdialysis and Locomotor Behavior}

Probes were prepared and implanted as previously described (Zestos et al, 2016). The effect of direct accumbal administration or subcutaneous (s.c.) injection of $6 \mathrm{c}$ on AMPH-induced neurochemical overflow and locomotion was investigated using a well-defined protocol (Zestos et al, 2016). The presence of $\mathbf{6 c}$ and AMPH in the brain after s.c. administration were detected by LC/MS. See Supplementary Methods for more details.

\section{Self-Administration}

The effect of $6 \mathrm{mg} / \mathrm{kg} 6 \mathrm{c}$ s.c. was evaluated on AMPH-self administration $(0.032 \mathrm{mg} / \mathrm{kg} /$ infusion $)$ and sucrose pellet self-administration under a fixed ratio (FR) 5 schedule of reinforcement. See Supplementary Methods for more details.

\section{Statistics}

The results were analyzed using the GraphPad Prism 6 software (San Diego, CA) and are plotted as mean \pm SEM. Statistical significance was determined using two-way repeated measures (RM) ANOVA, one-way ANOVA or a two-tailed Student's $t$-test. When concentration-response curves were compared, comparison of fits in non-linear regression was used to determine whether curves differed from each other. The null hypothesis was that the best-fit parameters for the values did not differ. A conclusion of statistical significance represents a rejection of the null hypothesis and indicates a difference between designated values. 


\section{RESULTS}

\section{6c Inhibits PKC in Synaptosomes}

Previously, we showed that $\mathbf{6 c}$ inhibits PKC activity 250 times more potently than tamoxifen in the human neuroblastoma cell line SHSY5Y and displayed a $K_{\mathrm{i}}>10 \mu \mathrm{M}$ at the ER $\alpha$ (Carpenter et al, 2016). Here we examined the effect of $\mathbf{6 c}$ on PKC activity in striatal synaptosomes, which contain dopaminergic terminals. To do this, we determined the effect of $\mathbf{6 c}$ on the phosphorylation of the PKC substrates GAP-43 and MARCKS at the PKC-specific phosphorylation sites $\operatorname{ser}^{41}$ and ser $^{152 / 156}$, respectively (Heemskerk et al, 1993; Nielander et al, 1990). 6c decreased both GAP-43 and MARCKS phosphorylation in a concentration-dependent manner up to $3 \mu \mathrm{M}$ but showed greater potency in inhibition of GAP-43 phosphorylation as compared with MARCKS (Figure 1b). The $\mathrm{IC}_{50}$ of 6c for inhibition of PMA-stimulated phosphoser ${ }^{41}$-GAP-43 was $30 \mathrm{nM}(95 \%$ confidence interval $(\mathrm{CI}), 9-98 \mathrm{nM}, n=4)$ while that for inhibition of phosphoser ${ }^{152 / 156}$-MARCKS was $189 \mathrm{nM}$ ( $95 \% \mathrm{CI}, 25-1460 \mathrm{nM}, n=5)$ ). A comparison of fits in Prism 6 showed that the two $\mathrm{IC}_{50}$ s were significantly different $\left(\mathrm{F}_{(2,45)}=7.7, p<0.01\right)$.

\section{6c Asymmetrically Blocks AMPH-Stimulated Dopamine Efflux and Uptake}

We showed that selective PKC inhibitors reduce AMPHstimulated dopamine release in vitro (Kantor and Gnegy, 1998). Using suprafusion of striatal synaptosomes, the effect of the PKC inhibitor $\mathbf{6 c}$ on AMPH-stimulated dopamine efflux was tested. Synaptosomes were incubated with $\mathbf{6 c}$ for $1 \mathrm{~h}$ before AMPH exposure. 6c effectively and dosedependently reduced dopamine efflux induced by $10 \mu \mathrm{M}$ AMPH (Figure 2a). No concentration of $\mathbf{6 c}$ tested affected basal dopamine release (Supplementary Figure S1). Our group has shown that PKC inhibitors exhibit asymmetry in their effects on DAT activity, where the compounds preferentially block dopamine efflux without having significant effects on $\left[{ }^{3} \mathrm{H}\right]$ dopamine uptake (Johnson et al, 2005; Zestos et al, 2016). The effect of a $1 \mathrm{~h}$ pretreatment of $0.3-3 \mu \mathrm{M} 6 \mathrm{c}$ on $\left[{ }^{3} \mathrm{H}\right]$ dopamine uptake was determined in striatal synaptosomes. Only $3 \mu \mathrm{M} \mathbf{6 c}$ had a significant effect on dopamine uptake, reducing $\left[{ }^{3} \mathrm{H}\right]$ dopamine uptake by $60 \%$ compared with the vehicle treatment (Figure $2 \mathrm{~b}$ ). Calculation of the dose-dependent percentage of inhibition of dopamine efflux and uptake demonstrates a 4.6-fold selectivity for efflux over influx (Figure 2c).

\section{$6 c$ Does not Affect DAT Trafficking and Does Not Displace $\left[{ }^{3} \mathrm{H}\right]$ WIN 35,428 Binding}

Two potential explanations for the effect of $\mathbf{6 c}$ on dopamine uptake or efflux are that the compound is altering surface transporter levels or that it is directly binding to DAT. After incubating rat striatal synaptosomes with $3 \mu \mathrm{M} 6 \mathrm{c}$ for $1 \mathrm{~h}$ at $37^{\circ} \mathrm{C}$, our biotinylation studies showed that the compound did not cause a change in DAT surface levels as compared with vehicle (Figure 3). Many dopamine uptake blockers, such as cocaine, interact with a binding site close to the substrate site and hence reduce the normal uptake functioning at DAT (Beuming et al, 2008). To investigate whether $\mathbf{6 c}$ is directly binding at this site, we tested the ability of the compound to alter binding of the cocaine analog $\left[{ }^{3} \mathrm{H}\right]$ WIN 35,428 . We found that treating synaptosomes with $3 \mu \mathrm{M} \mathbf{6 c}$ for $1 \mathrm{~h}$ at $37^{\circ} \mathrm{C}$ caused no changes in the subsequent equilibrium binding of $\left[{ }^{3} \mathrm{H}\right]$ WIN 35,428 . The $K_{\mathrm{d}}$ for $\left[{ }^{3} \mathrm{H}\right]$ WIN 35,428 in the absence or presence of $6 c$ in $n M \pm$ SEM was $77 \pm 17$ and $71 \pm 19$, respectively. The $B_{\max }$ for $\left[{ }^{3} \mathrm{H}\right] \mathrm{WIN}$ 35,428 binding in the absence or presence of $6 \mathrm{c}$ in $\mathrm{pmol} / \mathrm{mg}$ protein \pm SEM was $2.4 \pm 0.4$ and $2.2 \pm 0.3$, respectively, $n=3$.

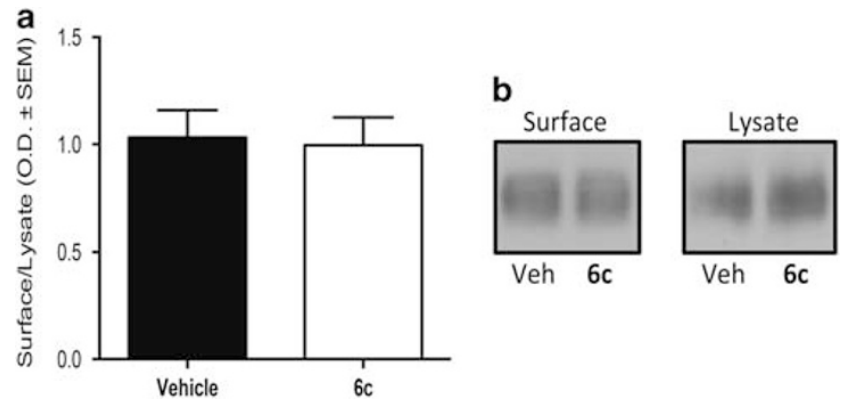

Figure 3 The action of $\mathbf{6 c}$ on DAT surface expression. (a) Rat striatal synaptosomes were incubated in the presence or absence of $3 \mu \mathrm{M} \mathbf{6 c}$ for I h at $37^{\circ} \mathrm{C}$, followed by the biotinylation of surface DAT as previously described in Methods section. (b) Representative western blots. Data shown as mean $\pm \operatorname{SEM}(n=5)$.
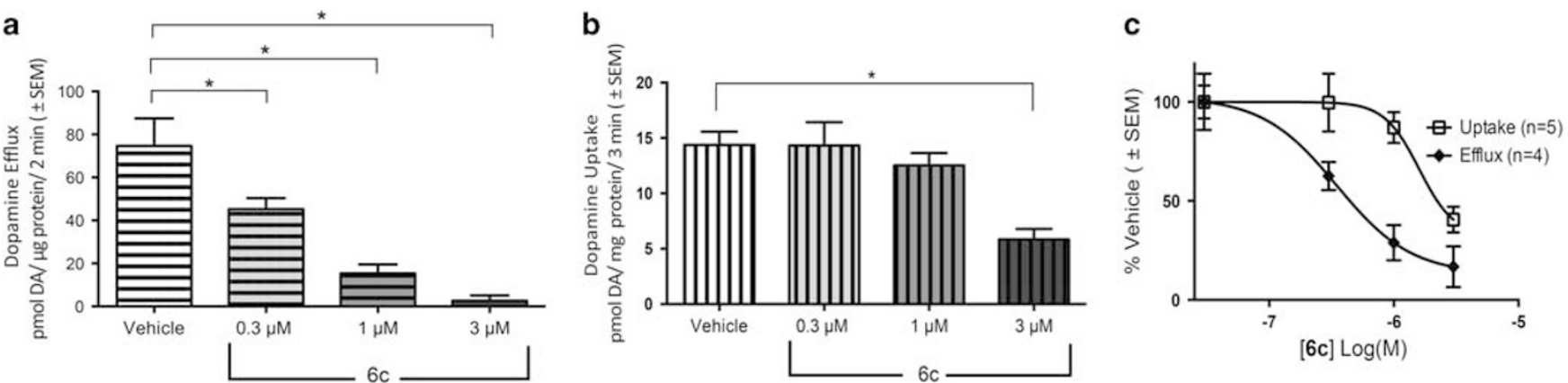

Figure 2 6c Modulation of DAT efflux and uptake processes. (a) Rat striatal synaptosomes were incubated in the presence or absence of $\mathbf{6 c}$ for I $\mathrm{h}$ at $37^{\circ}$ C; efflux was stimulated with $10 \mu M$ AMPH $(n=4)$. Post hoc Dunnett multiple comparison test, $* p \leqslant 0.05$. (b) Synaptosomes were incubated with vehicle or 6c for I h at $37^{\circ} \mathrm{C}$ and $\left[{ }^{3} \mathrm{H}\right]$ dopamine uptake was quantified $(n=5)$. Post hoc Dunnett multiple comparison test, $* p<0.01$. (c) Efflux and uptake results represented as the percentage of vehicle. All points are mean \pm SEM. 

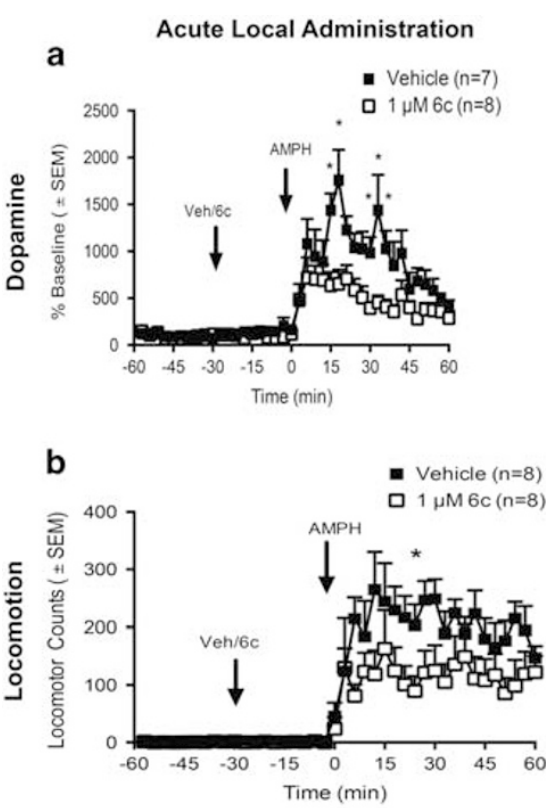
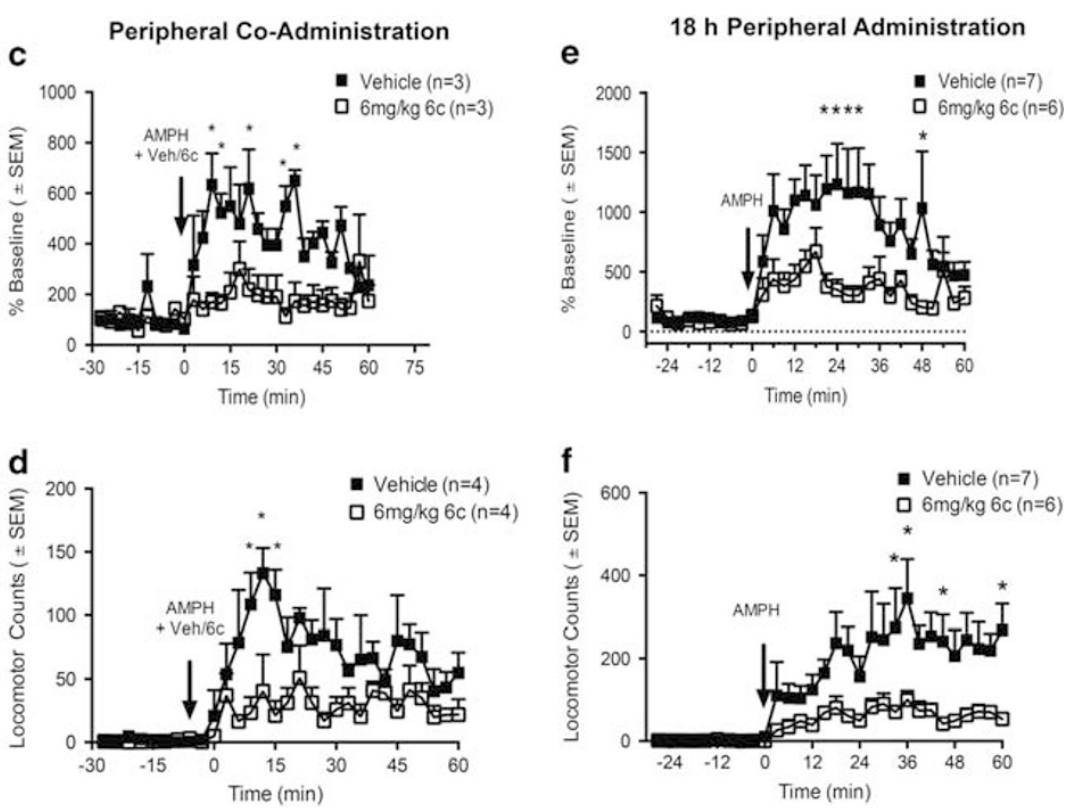

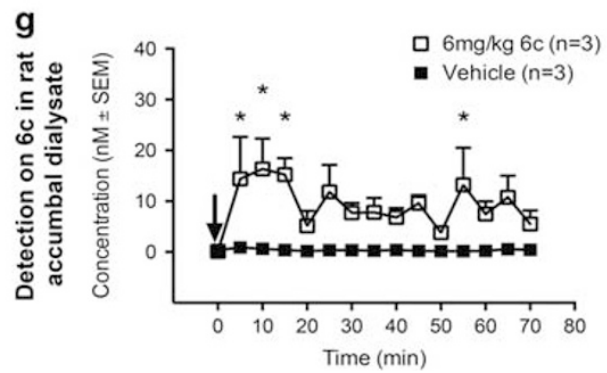

Figure 4 The effect of $\mathbf{6 c}$ on in vivo AMPH-induced dopamine overflow and locomotion. (a, b) In all, I $\mu M \mathbf{6 c}$ or vehicle was perfused into the nucleus accumbens using retrodialysis $30 \mathrm{~min}$ prior to the administration of $2 \mathrm{mg} / \mathrm{kg}$ i.p. AMPH. (a) Dopamine overflow; vehicle $(n=7)$ and $\mathbf{6 c}(n=8)$. Post hoc Sidak's multiple comparison test, ${ }^{*} p<0.05$. (b) Locomotion; in post hoc Sidak's multiple comparison test, ${ }^{*} p<0.05$; vehicle $(n=8), \mathbf{6 c}(n=8)$. (c, d) In all, 6 mg/kg $\mathbf{6 c}$ or vehicle were given to rats s.c. simultaneously with I mg/kg i.p. AMPH. (c) Dopamine overflow; post hoc Sidak's multiple comparison test, * $<<0.05$; vehicle $(n=3), \mathbf{6 c}(n=3)$. (d) Locomotor activity; post hoc Sidak's multiple comparison test, $* p<0.01$; vehicle $(n=4), \mathbf{6 c}(n=4)$. (e, f) ln all, $6 \mathrm{mg} / \mathrm{kg} \mathbf{6 c}$ or vehicle was given $18 \mathrm{~h}$ prior to the administration of $2 \mathrm{mg} / \mathrm{kg}$ i.p. amphetamine (AMPH). (e) In post hoc Sidak's multiple comparison test, $* p<0.05$ for dopamine overflow. (f) Post hoc Sidak's multiple comparison test, $* p<0.05$ for locomotion. For dopamine and locomotor activity, vehicle $(n=7)$ and $\mathbf{6 c}(n=6)$. (g) In all, $6 \mathrm{mg} / \mathrm{kg}$ $\mathbf{6 c}$ or vehicle $(n=3)$ was administered s.c., and dialysate collected from time 0 to 70 min. Post hoc Sidak's multiple comparison test, $* p<0.05$. Levels of $\mathbf{6 c}$ were quantified using LC-MS and corrected for recovery.

\section{Direct Accumbal and Systemic Administration of $6 c$ Decreases AMPH-Stimulated Dopamine Overflow and Locomotion}

To assess whether the effect of $\mathbf{6 c}$ on reduction of AMPHstimulated dopamine efflux in synaptosomes would occur in vivo, we conducted a series of microdialysis experiments in which dopamine overflow and locomotor activity were measured simultaneously. In the first experiment, we collected baseline samples for $30 \mathrm{~min}$, and then $1 \mu \mathrm{M} \mathbf{6 c}$ was perfused directly into the nucleus accumbens core $30 \mathrm{~min}$ prior to the peripheral administration of $2 \mathrm{mg} / \mathrm{kg}$ AMPH. As shown in Figure 4a, $6 \mathbf{c}$ significantly reduced AMPH-stimulated dopamine overflow in freely moving rats at a concentration that did not reduce dopamine uptake (two-way RM ANOVA, $\mathrm{F}_{(39,507)}=22.42, p<0.0001$ for time; $\mathrm{F}_{(1,13)}=7.23, p<0.05$ for drug; and $\left.\mathrm{F}_{(39,}, 507\right)=4.04$, $p<0.0001$ for time-drug interaction). Similarly, as depicted in Figure $4 \mathrm{~b}$, locomotor activity in response to the injection of AMPH was significantly reduced (two-way RM ANOVA,
$\mathrm{F}_{(39,546)}=19.15, p<0.0001$ for time; $\mathrm{F}_{(1,14)}=4.26, p=0.058$ for drug; and $\mathrm{F}_{(39,546)}=1.92, p<0.01$ for interaction of drug and time).

Because $6 \mathrm{c}$ was designed on the scaffold of the CNSpermeant drug, tamoxifen, there was some expectation that it might cross the blood-brain barrier. To test this possibility, we administered the compound systemically and checked for its presence in the nucleus accumbens using microdialysis coupled to LC-MS. In all, $6 \mathrm{mg} / \mathrm{kg} \mathbf{6 c}$ s.c. resulted in detectable levels of the compound in the nucleus accumbens (Figure 4g, two-way RM ANOVA, $\mathrm{F}_{(1,4)}=22.53, p<0.01$ for drug). The data demonstrate that $\mathbf{6 c}$ peaks in the brain within $10 \mathrm{~min}$ and remains relatively steady at concentrations between 10 and $20 \mathrm{nM}$ over the next hour. Estimated percentage of recovery through the probe was $10-15 \%$ and was used to calculate the concentration of $6 \mathrm{c}$ in vivo.

Based upon the rapid appearance of $\mathbf{6} \mathbf{c}$ in the brain after peripheral injection, we examined if s.c. administration of $\mathbf{6 c}$ with AMPH would reduce the effects of AMPH on dopamine 
a

Vehicle-AMPH Training Group $(n=6)$

$\square$ 6c-AMPH Training Group $(n=6)$

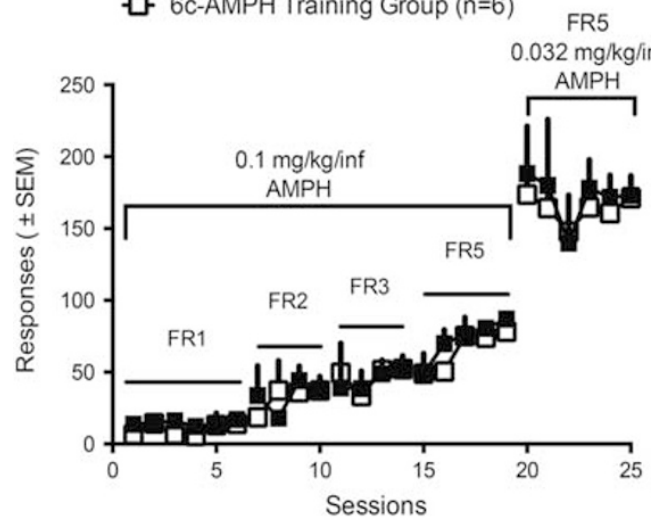

c
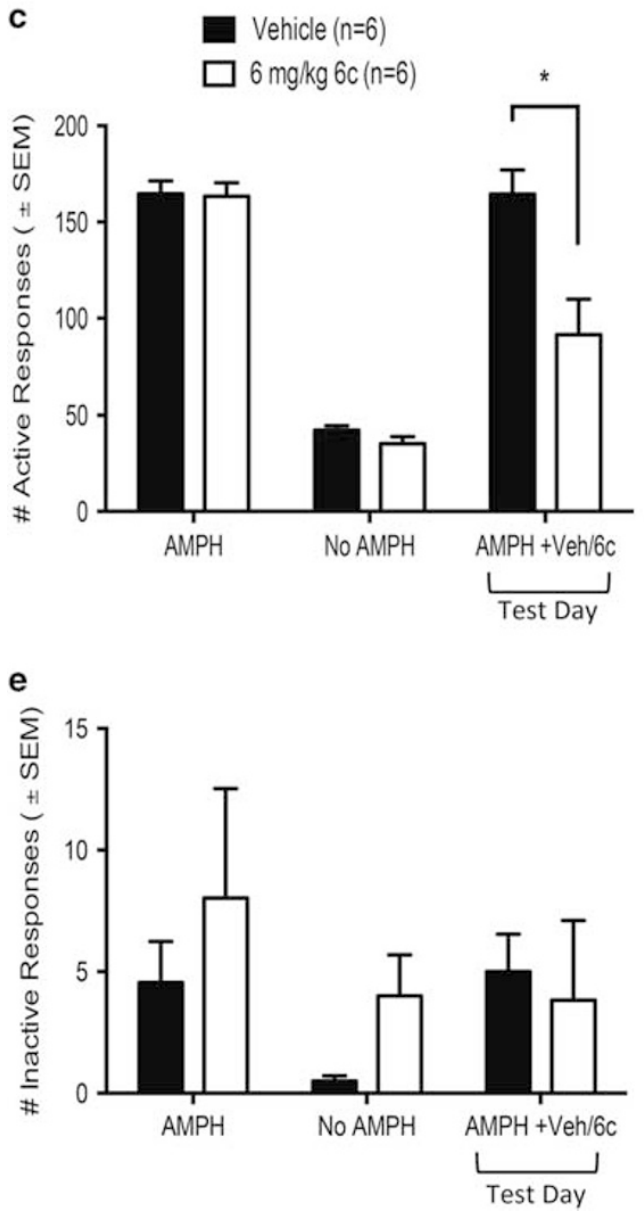

b

Vehicle-Food Training Group ( $n=6)$

6c-Food Training Group ( $n=6)$

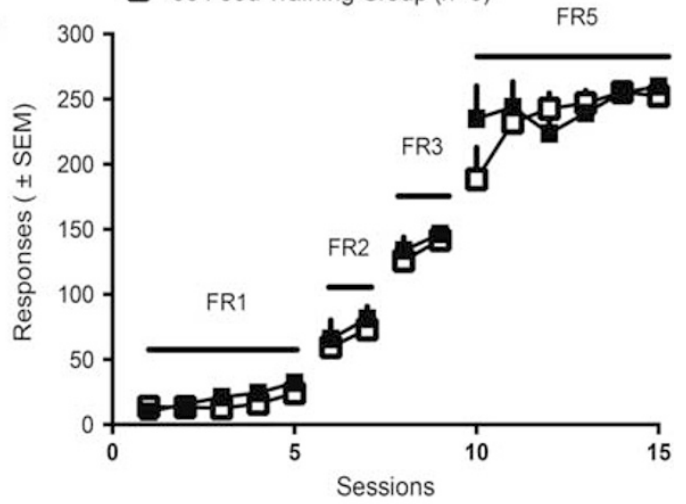

d

Vehicle $(n=6)$

$6 \mathrm{mg} / \mathrm{kg} 6 \mathrm{c}(\mathrm{n}=6)$

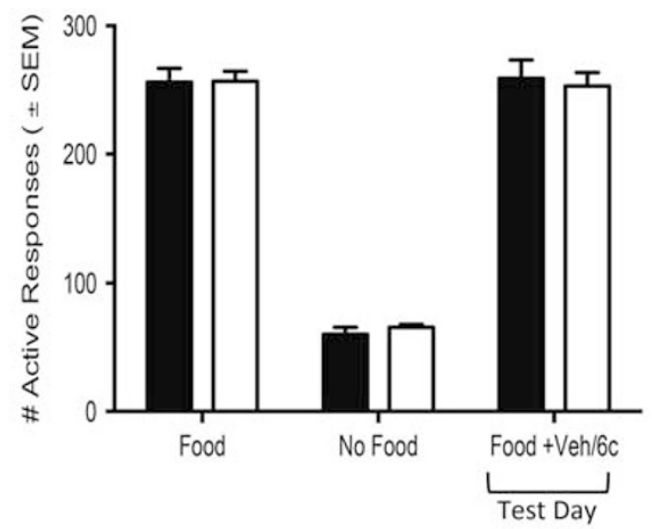

f

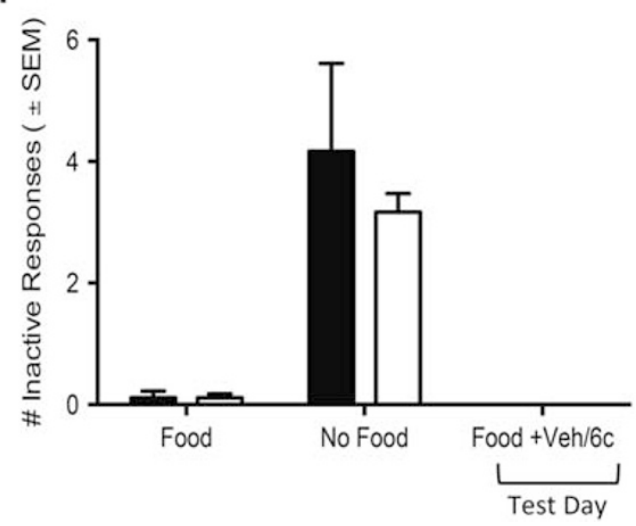

Figure 5 The effect of $6 \mathrm{mg} / \mathrm{kg}$ s.c. $\mathbf{6 c}$ on AMPH and food self-administration. (a) Training data for rats used in AMPH self-administration experiments. Rats were escalated from a FRI to a FR5 schedule with $0.1 \mathrm{mg} / \mathrm{kg} /$ infusion of AMPH. Finally rats were trained to stably administer on the FR5 schedule with $0.032 \mathrm{mg} / \mathrm{kg} /$ infusion of AMPH. (b) Training data for rats used in food self-administration. Rats escalated from a FRI to a FR5 schedule for food pellets. (c) On test day, $6 \mathrm{mg} / \mathrm{kg} \mathbf{6 c}$ or vehicle was given $18 \mathrm{~h}$ prior to AMPH self-administration session. Post hoc Sidak's multiple comparison test, *p $<0.000 \mathrm{I}$, a significant difference between vehicle- and $\mathbf{6 c}$-treated rats. (d) On test day, $6 \mathrm{mg} / \mathrm{kg} \mathbf{6 c}$ or vehicle was given $18 \mathrm{~h}$ prior to food self-administration session. (e, f) Inactive nose poke responses during AMPH and food self-administration sessions, respectively. All data sets are represented as mean \pm SEM.

overflow and locomotion. As shown in Figure 4c, simultaneous s.c. injection of $6 \mathrm{mg} / \mathrm{kg}$ 6c and $1 \mathrm{mg} / \mathrm{kg}$ AMPH resulted in a significant decrease in dopamine overflow as compared with AMPH alone (two-way RM ANOVA $\mathrm{F}_{(29}$, 116) $=5.17, p<0.0001$ for time; $\mathrm{F}_{(1,4)}=16.15, p<0.05$ for drug; and $\mathrm{F}_{(29,116)}=2.85, p<0.0001$ for interaction of drug and time). Figure $4 \mathrm{~d}$ demonstrates that administration of $\mathbf{6 c}$ elicited a corresponding significant decrease in AMPHstimulated locomotor behavior compared with AMPH alone (two-way RM ANOVA, $\mathrm{F}_{(29,174)}=6.45, p<0.0001$ for time; $\mathrm{F}_{(1,6)}=15.82, p<0.01$ for drug; and $\mathrm{F}_{(29,174)}=1.95, p<0.01$ for drug and time interaction). To rule out whether $\mathbf{6 c}$ was 
simply reducing the amount of AMPH getting into the brain, we tested the concentrations of AMPH in the brain after $\mathbf{6 c}$ was given s.c. with AMPH. Administration of s.c. $6 \mathrm{c}$ with $1 \mathrm{mg} / \mathrm{kg}$ AMPH had no effect on the AMPH levels achieved in the nucleus accumbens when compared with rats treated with vehicle and $1 \mathrm{mg} / \mathrm{kg}$ AMPH (Supplementary Figure S2).

We next queried whether pretreatment with $6 \mathrm{c}$ had extended effects. A s.c. injection of $6 \mathrm{c}$ was given $18 \mathrm{~h}$ prior to $\mathrm{AMPH}$ and $\mathrm{AMPH}$-stimulated dopamine overflow and locomotor behavior were measured. As shown in Figure 4e, pretreatment with $6 \mathrm{mg} / \mathrm{kg}$ 6c s.c. $18 \mathrm{~h}$ prior to an injection of $2 \mathrm{mg} / \mathrm{kg}$ AMPH i.p. significantly decreased AMPHstimulated dopamine overflow (in two-way RM ANOVA, $\mathrm{F}_{(29,319)}=9.05, p<0.0001$ for time; $\mathrm{F}_{(1,11)}=5.05, p<0.05$ for drug; and $\mathrm{F}_{(29,319)}=2.87, p<0.0001$ for drug and time interaction). Again, there was a corresponding decrease in the locomotor response to AMPH (Figure 4f) following 6c pretreatment (in two-way RM ANOVA, $\mathrm{F}_{(29,319)}=7.97$, $p<0.0001$ for time; $F_{(1,11)}=9.87, p<0.01$ for drug; and $F_{(29}$, 319) $=2.56, p<0.0001$ for interaction of time and drug). Although higher than null value, only low picomolar levels of 6c were detected in accumbal dialysate $18 \mathrm{~h}$ after s.c. administration (data not shown).

\section{Systemic 6c Reduces AMPH-Self Administration But Not Food Self-Administration}

As 6c effectively reduced AMPH neurochemical and behavioral effects in vivo, we next investigated whether the tamoxifen analog could effectively reduce the reinforcing effects of AMPH in a rat model of self-administration. Rats were trained to administer AMPH i.v. on a FR5 schedule of reinforcement and both groups of rats in the AMPH selfadministration studies demonstrated similar patterns of responding for AMPH during training (Figure 5a). As shown in Figure $5 c, 18 \mathrm{~h}$ following s.c. injection of $6 \mathrm{c}$, the number of infusions of AMPH earned over a $1 \mathrm{~h}$ session significantly decreased compared with the vehicle-treated animals (in twoway $\mathrm{RM}$ ANOVA, $\mathrm{F}_{(2,20)}=76.56, p<0.0001$ for responses; $\mathrm{F}_{(1,10)}=12.90, p<0.01$ for drug; and $\mathrm{F}_{(2,20)}=7.25, p<0.01$ for interaction of infusion and drug). In a similar procedure, rats were trained to self-administer sucrose pellets on a FR5 schedule of reinforcement in $20 \mathrm{~min}$ daily sessions. Again, both groups of rats in the food self-administration studies demonstrated similar patterns of responding for food pellets during training (Figure 5b). We found that $18 \mathrm{~h}$ pretreatment with $6 \mathrm{mg} / \mathrm{kg} 6 \mathrm{c}$ did not alter the number of active nose poke responses as compared with vehicle pretreatment (Figure 5d). There were no significant differences in the rats responding at the inactive nose poke for either the AMPH or food selfadministration experiments (Figures $5 \mathrm{e}$ and $\mathrm{f}$ ).

\section{Discussion}

In this paper, we report our findings on a novel tamoxifen analog and PKC inhibitor that modulates DAT functioning. It is well known that phosphorylation serves as a major regulator of DAT expression and activity (Foster et al, 2006). Enhanced PKC activity results in internalization of DAT, although a direct mechanism linking DAT phosphorylation and internalization has not been elucidated (Zahniser and
Doolen, 2001). DAT contains PKC consensus sites (Foster et al, 2002) in its N-terminal domain and truncation of this region attenuates DAT phosphorylation induced by the PKC activator PMA (Granas et al, 2003). Phosphorylation of DAT in the N-terminus has been reported to be permissive for AMPH-stimulated dopamine efflux with no effect on dopamine influx (Khoshbouei et al, 2004; Wang et al, 2016). Several reports have shown that PKC inhibitors reduce dopamine release (Kantor and Gnegy, 1998; Loweth et al, 2009; Zestos et al, 2016) while treatment of striatal synaptosomes with PKC activators stimulates dopamine efflux (Cowell et al, 2000; Opazo et al, 2010). We previously demonstrated that specific inhibitors of $\mathrm{PKC} \beta$ inhibit AMPH-stimulated dopamine overflow and locomotor activity when administered directly into the core of the nucleus accumbens (Zestos et al, 2016).

\section{In Vitro Studies}

AMPH-induced dopamine efflux is central to the abuse liability of the stimulant. Therefore, we hypothesize that a CNS-permeant PKC inhibitor may be therapeutically beneficial in the treatment of AMPH abuse. As the only CNS-permeant PKC inhibitor, tamoxifen, causes undesirable ER-mediated side effects, we used previously available SAR information to create a CNS-permeant PKC inhibitor lacking ER affinity (Carpenter et al, 2016). As shown in Figures $1 \mathrm{~b}$ and $c, 6 c$ reduced PMA-stimulated PKC activity in striatal synaptosomes. Moreover, the compound demonstrated selectivity for PKC substrates, in that its inhibitory activity was more potent for phospho-GAP-43 than for phosphoMARCKS. Tamoxifen acts as an allosteric inhibitor of PKC by interacting with its regulatory domain and competing with phospholipids (O'Brian et al, 1985). It is possible that the mechanism of action of $\mathbf{6 c}$ at PKC is also at the regulatory site but further studies must be undertaken to confirm this. An action at a regulatory subunit of PKC, similar to that of tamoxifen, could explain the differential effect on substrates.

There was also a differential potency of $6 c$ on the direction of dopamine transport in that $\mathbf{6 c}$ more potently inhibited reverse transport of dopamine than inward transport. This observation is comparable to, but not identical to our previous studies examining the effects of PKC $\beta$ inhibitors on DAT. We and others have reported that PKC inhibitors, including specific $\mathrm{PKC} \beta$ inhibitors, reduce AMPH-stimulated dopamine efflux but have no effect on dopamine uptake (Browman et al, 1998; Loweth et al, 2009; Zestos et al, 2016). The asymmetric regulation of DAT is possible because forward and reverse transport appear to be mediated by different factors (Sitte and Freissmuth, 2015). For example, the DAT ligand SoRI-20041 inhibited substrate uptake with no significant effects on efflux (Rothman et al, 2009; Schmitt et al, 2013). 6c has different effects on DAT from the standard PKC inhibitors, however, because at higher concentrations it will inhibit dopamine uptake. This suggests that the compound might interact directly with DAT, although not at the cocaine-binding site as up to $3 \mu \mathrm{M} 6 \mathrm{c}$ had no effect on the binding of $\left[{ }^{3} \mathrm{H}\right] \mathrm{WIN}$ 35,428 . Although the cocaine- and dopamine-binding sites on DAT overlap, they are not the same (Beuming et al, 2008). Therefore, it is possible, albeit unlikely, that $\mathbf{6 c}$ can directly bind to DAT and affect substrate but not cocaine binding. 
The biotinylation experiments showed that the inhibition of dopamine uptake could not be attributed to a reduction in cell-surface DAT. It is possible that the diphenyl structural motif in $6 \mathrm{c}$ could partially account for its blockade of dopamine uptake because this motif also exists in atypical DAT blockers such as modafinil and benztropine, which appear to bind preferentially to the inward-facing conformation of DAT (Reith et al, 2015; Schmitt et al, 2013). In addition to the well-characterized substrate site (S1), crystal structures of the bacterial leucine transporter (Zhen and Reith, 2016), the drosophila DAT, and the serotonin transporter show the presence of secondary allosteric sites (S2 and S3), where compounds can bind and modify the conformation and function of DAT (Reith et al, 2015; Schmitt et al, 2013). It is possible that $\mathbf{6 c}$ could occupy one of these allosteric sites. Alternatively, the effect on uptake could be through an as yet unidentified mediator.

\section{In Vivo Studies}

We previously demonstrated that direct administration of specific inhibitors of $\mathrm{PKC} \beta$ via retrodialysis into the nucleus accumbens inhibits AMPH-stimulated dopamine overflow and locomotor activity (Zestos et al, 2016). This result was recapitulated with the structurally unrelated $6 \mathrm{c}$, using a concentration $(1 \mu \mathrm{M})$ that did not disrupt inward transport in our in vitro studies. A notable advantage of $6 c$ over the other inhibitors, however, is that it can cross the blood-brain barrier, like its parent compound tamoxifen. We found that giving $6 \mathrm{mg} / \mathrm{kg} \mathbf{6 c}$ s.c. led to detectable levels of the compound in the brain within the first 5 min following administration. The maximally measured concentration of $6 c$ in the brain was approximately $15 \mathrm{nM}$, but it appeared biologically active even at that concentration. Simultaneous s.c. injection of $6 \mathrm{mg} / \mathrm{kg}$ 6c with $1 \mathrm{mg} / \mathrm{kg}$ AMPH resulted in a rapid reduction in both dopamine overflow and locomotor behavior. Therefore, despite the seemingly low level, the compound was active. Also, the low concentration of $\mathbf{6 c}$ in the nucleus accumbens was comparable to the $\mathrm{IC}_{50}$ of $\mathbf{6 c}$ for inhibition of GAP-43 phosphorylation in synaptosomes (Figure $1 b$ ).

Our ultimate goal is to determine whether $6 \mathrm{c}$ would alter the reinforcing properties of AMPH. Therefore, we measured the effect of s.c. administration of the compound on AMPH self-administration. As previously mentioned, giving $6 \mathrm{c} 18 \mathrm{~h}$ prior to AMPH significantly decreased AMPH-induced dopamine overflow and locomotion. In agreement with this, we found that administering $6 \mathrm{mg} / \mathrm{kg} 6 \mathrm{c} 18 \mathrm{~h}$ prior to a AMPH self-administration session significantly reduced responding on the active nose poke manipulandum as compared with vehicle pretreatment (Figure $5 c$ ). This finding serves as direct evidence that $\mathbf{6 c}$ decreases on-going $\mathrm{AMPH}$ self-administration. Ultimately, we are interested in investigating how $\mathbf{6 c}$ affects the inverted U-shaped dose-response curve for AMPH self-administration and whether the results obtained in this current study translate to other schedules of reinforcement, such as a progressive ratio schedule. The lack of effect of $\mathbf{6 c}$ on sucrose self-administration demonstrates that the drug did not alter responding for all reinforcers and did not suppress all operant responding.

We are in the process of performing time-course studies documenting the onset and duration of the ability of $6 \mathrm{c}$ to reduce the neurochemical and behavioral effects of AMPH in vivo. Nonetheless, it is highly interesting that, $18 \mathrm{~h}$ after $\mathrm{s}$. c. administration, $6 \mathrm{c}$ can still produce a reduction in AMPHstimulated dopamine overflow and locomotor activity. Our measurement of $\mathbf{6 c}$ in the nucleus accumbens showed that it is still present, albeit at extremely low levels. Nothing is known of the metabolism of this compound, but it is possible that there is a long-lasting metabolite that remains active. Another explanation is that the initial action of the compound, perhaps PKC inhibition, elicits a long-term change in downstream signaling that maintains inhibition of AMPH action. A limitation to our methodology for measuring $6 \mathrm{c}$ levels in the brain is that it only reflects extracellular concentrations. It is therefore also conceivable that the long-term effects of $\mathbf{6 c}$ could be due to intracellular accumulation of the compound, which we did not sample.

$\mathrm{PKC}$ is widely expressed in the body and is involved in a diverse collection of GPCR and growth factor-dependent cellular pathways. Therefore, there are concerns that targeting the enzyme could lead to significant, unwanted side effects. However, clinical work with PKC inhibitors proves otherwise. For instance, chronic tamoxifen administration is generally well tolerated by women and selective PKC inhibitors have not caused severe toxicities in clinical studies (Mochly-Rosen et al, 2012). Recent findings suggest that PKC inhibitors would be useful in other CNS disorders, such as Alzheimer's disease where activating forms of PKC $\alpha$ support $\mathrm{A} \beta$ activity (Alfonso et al, 2016). A total block of PKC activity is likely not required for adequate treatment; if increases in PKC activity are involved in a particular pathology, reduction to normal levels could be effective. Repeated treatment with AMPH, for example, leads to an increase in striatal PKC activity in rats (Iwata et al, 1997). Development of inhibitors selective for specific isozymes or substrate-specific inhibitors would increase the utility of PKC inhibitors. Our data showing greater potency of $\mathbf{6 c}$ for inhibition of phosphorylation of GAP-43 over that of MARCKS demonstrates that substrate selectivity is possible, especially if the drug does not act directly at the ATPsubstrate-binding site on the PKC isozyme. We are hopeful in the possibility of creating even more selective CNSpermeant tamoxifen analogs and also implementing tools that will allow site-specific targeting of these compounds.

In summary, this study presents a new CNS-permeant PKC inhibitor, $6 \mathrm{c}$, which attenuated in vitro and in vivo neurochemical and behavioral effects of AMPH. Furthermore, systemic administration of $\mathbf{6 c}$ significantly reduced AMPH self-administration without generally suppressing behavior. These findings further support the targeting of PKC for the treatment of AMPH abuse and also illuminate the use of tamoxifen as a scaffold to create a new generation of CNS-permeant PKC inhibitors. Additionally, 6c may serve as a useful tool for investigating other PKC-related brain disorders, such as bipolar mania (Mochly-Rosen et al, 2012).

\section{FUNDING AND DISCLOSURE}

This work was supported by National Institute of Health R01 DA 11697, R37EB003320, T32 DA 007268, T32-GM007767, Howard Hughes International Research Fellowship, and the University of Michigan Endowment for Basic Sciences. The authors declare no conflict of interest. 


\section{REFERENCES}

Alfonso SI, Callender JA, Hooli B, Antal CE, Mullin K, Sherman MA et al (2016). Gain-of-function mutations in protein kinase Calpha (PKCalpha) may promote synaptic defects in Alzheimer's disease. Sci Signal 9: ra47.

Berman S, O'Neill J, Fears S, Bartzokis G, London ED (2008). Abuse of amphetamines and structural abnormalities in the brain. Ann NY Acad Sci 1141: 195-220.

Beuming T, Kniazeff J, Bergmann ML, Shi L, Gracia L, Raniszewska K et al (2008). The binding sites for cocaine and dopamine in the dopamine transporter overlap. Nat Neurosci 11: 780-789.

Browman KE, Kantor L, Richardson S, Badiani A, Robinson TE, Gnegy ME (1998). Injection of the protein kinase C inhibitor Ro31-8220 into the nucleus accumbens attenuates the acute response to amphetamine: tissue and behavioral studies. Brain Res 814: 112-119.

Carpenter C, Sorenson RJ, Jin Y, Klossowski S, Cierpicki T, Gnegy M et al (2016). Design and synthesis of triarylacrylonitrile analogues of tamoxifen with improved binding selectivity to protein kinase C. Bioorg Med Chem 24: 5495-5504.

Carvalho M, Carmo H, Costa VM, Capela JP, Pontes H, Remiao F et al (2012). Toxicity of amphetamines: an update. Arch Toxicol 86: 1167-1231.

Chen R, Furman CA, Zhang M, Kim MN, Gereau RW, Leitges M et al (2009). Protein kinase $C \beta$ is a critical regulator of dopamine transporter. J Pharmacol Exp Ther 328: 912-920.

Chiueh CC, Moore KE (1975). D-amphetamine-induced release of "newly synthesized" and "stored" dopamine from the caudate nucleus in vivo. J Pharmacol Exp Ther 192: 642-653.

Cowell RM, Kantor L, Hewlett GH, Frey KA, Gnegy ME (2000). Dopamine transporter antagonists block phorbol ester-induced dopamine release and dopamine transporter phosphorylation in striatal synaptosomes. Eur J Pharmacol 389: 59-65.

de Medina P, Favre G, Poirot M (2004). Multiple targeting by the antitumor drug tamoxifen: a structure-activity study. Curr Med Chem 4: 491-508.

Di Chiara G, Imperato A (1988). Drugs abused by humans preferentially increase synaptic dopamine concentrations in the mesolimbic system of freely moving rats. Proc Natl Acad Sci USA 85: $5274-5278$.

Fisher B, Costantino JP, Wickerham DL, Redmond CK, Kavanah M, Cronin WM et al (1998). Tamoxifen for prevention of breast cancer: report of the National Surgical Adjuvant Breast and Bowel Project P-1 Study. J Natl Cancer Inst 90: 1371-1388.

Foster JD, Cervinski MA, Gorentla BK, Vaughan RA (2006) Regulation of the dopamine transporter by phosphorylation. In: Sitte HH, Freissmuth M (eds). Neurotransmitter Transporters. Springer Berlin Heidelberg: Berlin, Heidelberg, Germany. pp $197-214$.

Foster JD, Pananusorn B, Vaughan RA (2002). Dopamine transporters are phosphorylated on $\mathrm{N}$-terminal serines in rat striatum. J Biol Chem 277: 25178-25186.

Furman CA, Chen R, Guptaroy B, Zhang M, Holz RW, Gnegy M (2009). Dopamine and amphetamine rapidly increase dopamine transporter trafficking to the surface: live cell imaging using total internal reflection fluorescence microscopy. J Neurosci 29: 3328-3336.

Giambalvo CT (1992). Protein kinase C and dopamine transport-1. Effects of amphetamine in vivo. Neuropharmacology 31: 1201-1210.

Giambalvo CT (2004). Mechanisms underlying the effects of amphetamine on particulate PKC activity. Synapse (New York, NY) 51: 128-139.

Gradishar WJ (2004). Tamoxifen-what next? Oncologist 9: 378-384.

Granas C, Ferrer J, Loland CJ, Javitch JA, Gether U (2003). $\mathrm{N}$-terminal truncation of the dopamine transporter abolishes phorbol ester- and substance $\mathrm{P}$ receptor-stimulated phosphorylation without impairing transporter internalization. J Biol Chem 278: 4990-5000.

Gundimeda U, Chen ZH, Gopalakrishna R (1996). Tamoxifen modulates protein kinase $\mathrm{C}$ via oxidative stress in estrogen receptor-negative breast cancer cells. J Biol Chem 271: 13504-13514.

Heemskerk FM, Chen HC, Huang FL (1993). Protein kinase C phosphorylates Ser152, Ser156 and Ser163 but not Ser160 of MARCKS in rat brain. Biochem Biophys Res Commun 190: 236-241.

Horgan K, Cooke E, Hallett MB, Mansel RE (1986). Inhibition of protein kinase $\mathrm{C}$ mediated signal transduction by tamoxifen. Biochem Pharmacol 35: 4463-4465.

Iwata SI, Hewlett GH, Ferrell ST, Kantor L, Gnegy ME (1997). Enhanced dopamine release and phosphorylation of synapsin I and neuromodulin in striatal synaptosomes after repeated amphetamine. J Pharmacol Exp Ther 283: 1445-1452.

Johnson LA, Guptaroy B, Lund D, Shamban S, Gnegy ME (2005). Regulation of amphetamine-stimulated dopamine efflux by protein kinase C beta. J Biol Chem 280: 10914-10919.

Jordan VC (2003). Tamoxifen: a most unlikely pioneering medicine. Nat Rev Drug Discov 2: 205-213.

Kantor L, Gnegy ME (1998). Protein kinase C inhibitors block amphetamine-mediated dopamine release in rat striatal slices. J Pharmacol Exp Ther 284: 592-598.

Khoshbouei H, Sen N, Guptaroy B, Johnson LA, Lund D, Gnegy ME et al (2004). N-terminal phosphorylation of the dopamine transporter is required for amphetamineinduced efflux. PLoS Biol 2: E78.

Kulkarni J, Garland KA, Scaffidi A, Headey B, Anderson R, de Castella A et al (2006). A pilot study of hormone modulation as a new treatment for mania in women with bipolar affective disorder. Psychoneuroendocrinology 31: 543-547.

Lien EA, Wester K, Lønning PE, Solheim E, Ueland PM (1991). Distribution of tamoxifen and metabolites into brain tissue and brain metastases in breast cancer patients. $\mathrm{Br} J$ Cancer 63: 641-645.

Loweth JA, Svoboda R, Austin JD, Guillory AM, Vezina P (2009). The PKC inhibitor Ro31-8220 blocks acute amphetamineinduced dopamine overflow in the nucleus accumbens. Neurosci Lett 455: 88-92.

McMillen BA (1983). CNS stimulants: two distinct mechanisms of action for amphetamine-like drugs. Trends Pharmacol Sci 4: 429-432.

Mochly-Rosen D, Das K, Grimes KV (2012). Protein kinase C, an elusive therapeutic target? Nat Rev Drug Discov 11: 937-957.

Nielander HB, Schrama LH, van Rozen AJ, Kasperaitis M, Oestreicher AB, Gispen WH et al (1990). Mutation of serine 41 in the neuron-specific protein B-50 (GAP-43) prohibits phosphorylation by protein kinase C. J Neurochem 55: 1442-1445.

O'Brian CA, Liskamp RM, Solomon DH, Weinstein IB (1985). Inhibition of protein kinase $\mathrm{C}$ by tamoxifen. Cancer Res 45: 2462-2465.

Opazo F, Schulz JB, Falkenburger BH (2010). PKC links Gq-coupled receptors to DAT-mediated dopamine release. J Neurochem 114: 587-596.

Parker EM, Cubeddu LX (1986). Effects of d-amphetamine and dopamine synthesis inhibitors on dopamine and acetylcholine neurotransmission in the striatum. I. Release in the absence of vesicular transmitter stores. J Pharmacol Exp Ther 237: 179-192. Reith ME, Blough BE, Hong WC, Jones KT, Schmitt KC, Baumann $\mathrm{MH}$ et al (2015). Behavioral, biological, and chemical perspectives on atypical agents targeting the dopamine transporter. Drug Alcohol Depend 147: 1-19.

Rothman RB, Dersch CM, Ananthan S, Partilla JS (2009). Studies of the biogenic amine transporters. 13. Identification of "agonist" and "antagonist" allosteric modulators of amphetamine-induced dopamine release. J Pharmacol Exp Ther 329: 718-728. 
Schmitt KC, Rothman RB, Reith ME (2013). Nonclassical pharmacology of the dopamine transporter: atypical inhibitors, allosteric modulators, and partial substrates. J Pharmacol Exp Ther 346: 2-10.

Sitte HH, Freissmuth M (2015). Amphetamines, new psychoactive drugs and the monoamine transporter cycle. Trends Pharmacol Sci 36: 41-50.

Su HD, Mazzei GJ, Vogler WR, Kuo JF (1985). Effect of tamoxifen, a nonsteroidal antiestrogen, on phospholipid/calcium-dependent protein kinase and phosphorylation of its endogenous substrate proteins from the rat brain and ovary. Biochem Pharmacol 34: 3649-3653.

Wang HY, Friedman E (1996). Enhanced protein kinase C activity and translocation in bipolar affective disorder brains. Biol Psychiatry 40: 568-575.

Wang Q, Bubula N, Brown J, Wang Y, Kondev V, Vezina P (2016). PKC phosphorylates residues in the $\mathrm{N}$-terminal of the DA transporter to regulate amphetamine-induced DA efflux. Neurosci Lett 622: 78-82.

Wise RA, Bozarth MA (1985). Brain mechanisms of drug reward and euphoria. Psychiatr Med 3: 445-460.
Zahniser NR, Doolen S (2001). Chronic and acute regulation of $\mathrm{Na}+/ \mathrm{Cl}$ - -dependent neurotransmitter transporters: drugs, substrates, presynaptic receptors, and signaling systems. Pharmacol Ther 92: 21-55.

Zarate CA Jr, Singh JB, Carlson PJ, Quiroz J, Jolkovsky L, Luckenbaugh DA et al (2007). Efficacy of a protein kinase C inhibitor (tamoxifen) in the treatment of acute mania: a pilot study. Bipolar Disord 9: 561-570.

Zarate CA, Manji HK (2009). Protein kinase C inhibitors: rationale for use and potential in the treatment of bipolar disorder. CNS Drugs 23: 569-582.

Zestos AG, Mikelman SR, Kennedy RT, Gnegy ME (2016). PKC $\beta$ inhibitors attenuate amphetamine-stimulated dopamine efflux. ACS Chem Neurosci 7: 757-766.

Zhen J, Reith ME (2016). Impact of disruption of secondary binding site S2 on dopamine transporter function. J Neurochem 138: 694-699.

Zhu J, Reith MEA (2008). Role of dopamine transporter in the action of psychostimulants, nicotine, and other drugs of abuse. CNS Neurol Disord Drug Targets 7: 393-409.

Supplementary Information accompanies the paper on the Neuropsychopharmacology website (http://www.nature.com/npp) 